Verbale Interaktion 


\section{Verbale Interaktion}

Studien zur Empirie und Methodologie der Pragmatik

Herausgegeben von Dieter Flader

J. B. Metzlersche Verlagsbuchhandlung Stuttgart 
CIP-Titelaufnahme der Deutschen Bibliothek

Verbale Interaktion : Studien zur Empirie und Methodologie der Pragmatik / hrsg. von Dieter Flader. - Stuttgart : Metzler, 1991

ISBN 978-3-476-00719-3

NE: Flader, Dieter [Hrsg.]

ISBN 978-3-476-00719-3

ISBN 978-3-476-03329-1 (eBook)

DOI 10.1007/978-3-476-03329-1

Dieses Werk einschließlich aller seiner Teile ist urheberrechtlich geschützt. Jede Verwertung außerhalb der engen Grenzen des Urheberrechtsgesetzes ist ohne Zustimmung des Verlages unzulässig und strafbar. Das gilt insbesondere für Vervielfältigungen, Übersetzungen, Mikroverfilmungen und die Einspeicherung und Verarbeitung in elektronischen Systemen.

(c) 1991 Springer-Verlag GmbH Deutschland Ursprünglich erschienen bei J. B. Metzlersche Verlagsbuchhandlung und Carl Ernst Poeschel Verlag GmbH in Stuttgart 1991 


\section{Inhalt}

Einleitung des Herausgebers 1

\section{Kommunikationsanalysen}

Sigrid Gebel/Agnes Speck

"Ich stells Ihnen eigentlich ganz frei worüber Sie sprechen möchten«

Untersuchung der Eröffnung von Therapiegesprächen 9

Gunter Senft

Mahnreden auf den Trobriand Inseln

Eine Fallstudie 27

Michael Hanke

maieutike techne

Zum Modell der sokratischen Gesprächstechnik 50

Helmut Richter

Regelmißbrauch und Regelexplikation in einem Platonschen Dialog 92

\section{Studien zur Methodologie der Pragmatik}

\section{Konrad Ehlich}

Funktional-pragmatische Kommunikationsanalyse

Ziele und Verfahren 127

Dieter Flader/Thilo von Trotha

Über den geheimen Positivismus und andere Eigentümlichkeiten der ethnomethodologischen Konversationsanalyse 144

Jochen Rehbein/Harrie Mazeland

Kodierentscheidungen

Zur Kontrolle interpretativer Prozesse bei der Kommunikationsanalyse 166 
Werner Nothdurft/Thomas Spranz-Fogasy

Gesprächsanalyse von Schlichtungs-Interaktion

Methodische Probleme und ihre Hintergründe 222

Stichwortregister 241

Hinweise zu den Autoren 244 